
\title{
25 Research Square \\ Factors Influencing Uptake of Sexually Transmitted Infections Screening Among Adolescent Female Sex Workers in Mukono District
}

Joan Nakkazi ( $\sim$ na2joa@gmail.com )

Uganda Martyrs University https://orcid.org/0000-0002-4367-0712

Miisa Nanyingi

Uganda Martyrs University

\section{Research}

Keywords: Sexually Transmitted Infections, Screening, Adolescent Female Sex Workers, Uganda

Posted Date: April 29th, 2020

DOI: https://doi.org/10.21203/rs.3.rs-25007/v1

License: (c) (1) This work is licensed under a Creative Commons Attribution 4.0 International License.

Read Full License 


\section{Abstract}

\section{Background}

Worldwide, more than 1 million Sexually Transmitted Infections (STIs) are acquired every day and female adolescents aged 10 to 19 years are almost twice more susceptible to STIs than boys of the same age. The highest STI prevalence has been reported among key populations such as Female Sex Workers (FSWs) and fisher folk. This study investigated the factors influencing uptake of sexually transmitted infections screening among Adolescent Female sex Workers (AFSWs) in Mukono district, Uganda.

\section{Methods}

In this cross-sectional descriptive and analytical study, a total of 355 AFSWs based on the streets, bars, lodges, hotels, brothels, landing sites and other entertainment places in Mukono district were recruited using snowball sampling. Data was collected using pre-tested semi-structured questionnaires through face to face interviews with the help of trained research assistants. Data collected was entered into EpiData and then exported to SPSS for analysis. Analysis was done at three levels; Univariate for descriptive summary, Bivariate to test for possible association between each independent variable and the outcome variable, and Multivariate logistic regression to control for possible confounding effects of the independent variables. Chi square $\left(\chi^{2}\right)$ test was done and $p$ value 0.05 used to determine the association.

\section{Results}

This study found that uptake of STIs screening among AFSWs was $32.1 \%$. AFSWs who reported that STI screening wasn't embarrassing were 3 times more likely to take-up STI screening than those who said uptake of STI screening was embarrassing $(P R=3.45,95 \% \mathrm{Cl}=1.96-6.09, \mathrm{P}=<0.001)$. AFSWs who reported that STI screening wasn't painful were 5 times more likely to take-up STI screening than those who said uptake of STI screening was painful $(P R=5.45,95 \% \mathrm{Cl}=2.78-10.66, \mathrm{P}=<0.001)$.

\section{Conclusion}

STIs screening rate among AFSWs in Mukono district was at $32.1 \%$. Individual factors (attitude) and health facility factors were found to be the real influencers of uptake of STI screening among AFSWs in Mukono district. We, therefore, recommend that government scales up provision of sexually transmitted infection screening to even cater for high risk and vulnerable groups to facilitate and increase access to STI screening.

\section{Plain English summary}

Sexually Transmitted Infections (STIs) refer to conditions caused by pathogens that can be acquired and transmitted through unprotected sexual intercourse such as cervical cancer, candida, HIV. Because majority of STIs are asymptomatic, screening uptake is of paramount importance for early detection 
followed by prompt treatment among high risk vulnerable groups such as Adolescent Female Sex Workers (AFSWs).

\section{Adolescence is a transitional phase of growth and development between childhood and adulthood and} an adolescent is any person between ages 10 and 19. Sex work is the exchange of money, goods or services for sex and he who practices sex work is a sex worker. Quite a number of reasons such as age, peer pressure and others may explain why adolescents engage in immoral behaviors including sex work.

In this STI screening uptake study, pre-tested semi-structured questionnaires were used to collect data from respondents on what was influencing their uptake of STI screening. Of the 355 respondents, majority 241 had never screened for STIs and 114 had screened.

The research priorities identified were individual factors (attitude) and health facility factors as real influencers of uptake of STI screening among AFSWs in Mukono district.

In conclusion, AFSWs require information related to STIs and its screening. Information dissemination can be intensified at clinical and non-clinical sites to increase awareness and improve accessibility to STI screening experience among high risk vulnerable groups in Mukono district, hence reduce the prevalence among AFSWs, avert the risk of complications and eliminate sustained transmission in the community.

\section{Background}

Sexually transmitted infections other than HIV are an important global health issue. Sexually transmitted infections (STIs) in general, and among adolescents in particular, are of paramount concern to all people who work on improving the health status of populations (WHO 2019). The majority of STIs have no symptoms or only mild symptoms that may not be recognized as an STI in some cases. STIs can have serious reproductive health consequences beyond the immediate impact of the infection itself such as infertility in women and STIs consequences are a major reason for health seeking behavior among women.

According to WHO (2016), more than 1 million STIs are acquired every day worldwide. Each year, there are an estimated 357 million new infections with 1 of 4 STIs: chlamydia (131 million), gonorrhea (78 million), syphilis ( 5.6 million) and trichomoniasis ( 143 million). Worldwide the highest reported rates of STIs are found among young people between 15 and 24 years; up to $60 \%$ of the new infections and half of all people living with HIV globally are in this age group. Females adolescents in the age range of 10 to 19 years are almost twice as susceptible to STIs than boys of the same age and one in 20 adolescents acquires a new STI each year (UNAIDS 2014).

The goal of STI screening is to identify and treat individuals with curable infections, reduce transmission to others, avoid or minimize long term consequences, identify other exposed and potentially infected individuals and decrease overall incidence and prevalence of infection. 
Since the International Conference on Population and Development in Cairo in 1994, attempts to date to promote the sexual health of young people have tended to focus on prevention, education and counseling for those who are not yet sexually active, while the provision of health services like STI screening to those who have already engaged in unprotected sexual activity and faced the consequences, including pregnancy, STIs or sexual violence, has lagged behind.

According to mukono district population data 2017, Mukono has a population of 807,923 people of which 403,117 are females and 141,990 are males. There are a high number of female adolescents aged $10-24$ years at $25 \%$ (213,638 people). It has a large population of fishing communities on the Islands and shores of Lake Victoria and has a high number of bars, lodges, hotels and brothels. These combined make sex work highly prevalent especially among adolescent girls and young women hence are at high risk of STI acquisition and transmission. In Mukono district, STI prevalence stands at $6.2 \%$ among females and 3.8\% for males (MOH status report 2018).

\section{Methods}

In this cross sectional descriptive and analytical study, snow ball sampling was used to recruit 355 adolescent female sex workers based on the streets, bars, lodges, hotels, brothels, landing sites and other entertainment places in Mukono. Mukono district lies in the central region of Uganda and it lies approximately $20 \mathrm{~km}$ East of Kampala along the highway which links Uganda to Kenya.

\section{Data collection methods}

Quantitative data was collected through face to face interviews using pretested semi-structured and selfadministered questionnaires with the help of trained research assistants. All potential participants who met the eligibility criteria were briefed about the study. Eligibility was assessed for respondents who expressed willingness to participate and consent to participate were sought from eligible participants.

\section{Quantitative data management and analysis}

Quantitative data collected was entered into EPI-DATA, cleaned, and then exported to SPSS for analysis at univariate, bivariate and multivariate level. Cross tabulations were used to show the proportions of AFSWs and uptake of STI screening per variable. Bivariate analysis was done using chi-square to test and show the factors that were associated with uptake of STI screening. Factors with a P-value $\leq 0.1$ at bivariate level were further analyzed at multivariate level using binary logistic regression analysis to determine the factors that were significantly and independently associated with uptake of STI screening. Using the binary logistic regression analysis model, the summary model generated $R^{2}=40.7 \%$. This means that the factors generated as influencing factors can only explain $40.7 \%$ of the observed situation.

\section{Results}


The results show that the proportion of AFSWs who had screened was $32.1 \%$ (114) while $67.9 \%$ (241) hadn't screened as shown in the Fig. 1.

Majority, 83 (72.8\%) of those who had screened were in the age group of 15-19 years and $158(65.6 \%)$ of those who had not screened were in the same age group $\left(\chi^{2}: 1.864, P=0.172\right)$, this therefore means that AFSWs age was not found to influence STI screening uptake.

None of the socio-demographic factors of the AFSWs including:-age, religion, marital status, occupation alongside sex work, base as AFSW, years of practice as sex worker, as well as location of residence of the AFSW had any significant relationship with the uptake of STI screening among AFSWs as presented in Table 1. 
Table 1

Bivariate analysis of socio-demographic factors influencing uptake of sexually transmitted infection screening in Mukono district

\begin{tabular}{|c|c|c|c|c|}
\hline Variable & Uptake (\%) & No uptake (\%) & $x^{2}$ & $\mathrm{p}$-value \\
\hline \multicolumn{5}{|l|}{ Age in years } \\
\hline $10-14$ & $31(27.2)$ & $83(34.4)$ & 1.864 & 0.172 \\
\hline $15-19$ & $83(72.8)$ & 158(65.6) & & \\
\hline \multicolumn{5}{|l|}{ Religion } \\
\hline Catholic & $34(29.8)$ & $69(28.6)$ & 5.887 & 0.208 \\
\hline Anglican & $45(39.5)$ & 73(30.3) & & \\
\hline Moslem & $22(19.3)$ & $71(29.5)$ & & \\
\hline Pentecostal & $11(9.6)$ & $20(8.3)$ & & \\
\hline Others & $2(1.8)$ & $8(3.3)$ & & \\
\hline \multicolumn{5}{|l|}{ Marital status } \\
\hline Single & $70(61.4)$ & 178(73.9) & 9.387 & 0.052 \\
\hline Married & $27(23.7)$ & $40(16.6)$ & & \\
\hline Cohabiting & $5(4.4)$ & $11(4.6)$ & & \\
\hline Divorced & $2(1.8)$ & $5(2.1)$ & & \\
\hline Separated & $10(8.8)$ & $7(2.9)$ & & \\
\hline \multicolumn{5}{|c|}{ Occupation alongside sex work } \\
\hline Hair dresser & $11(9.6)$ & $21(8.7)$ & 12.714 & 0.122 \\
\hline Barmaid & 22(19.3) & $33(13.7)$ & & \\
\hline Housemaid & $5(4.4)$ & $26(10.8)$ & & \\
\hline Housewife & $10(8.8)$ & $17(7.1)$ & & \\
\hline Business & $17(14.9)$ & $21(8.7)$ & & \\
\hline Teacher & $4(3.5)$ & $9(3.7)$ & & \\
\hline Entertainment & 22(19.3) & 47(19.5) & & \\
\hline Student & 22(19.3) & $67(27.8)$ & & \\
\hline Other & $1(0.9)$ & 0 & & \\
\hline \multicolumn{5}{|c|}{ Base as an AFSW } \\
\hline Streets & $26(22.8)$ & 43(17.8) & 5.965 & 0.427 \\
\hline
\end{tabular}




\begin{tabular}{|lllll|} 
Bars & $13(11.4)$ & $36(14.9)$ & & \\
Lodgers & $19(16.7)$ & $48(19.9)$ & & \\
Brothels & $3(2.6)$ & $9(3.7)$ & & \\
Landing sites & $9(7.9)$ & $27(11.2)$ & & \\
Other & $24(21.1)$ & $52(21.6)$ & & \\
Years of practice as sex worker & $20(17.5)$ & $26(10.8)$ & & \\
<one year & $19(16.7)$ & $54(22.4)$ & 2.641 & \\
1-2years & $53(46.5)$ & $115(47.7)$ & & \\
3-5years & $33(28.9)$ & $59(24.5)$ & & \\
Over 5years & $9(7.9)$ & $13(5.4)$ & & \\
Location of residence & & & & \\
Urban & $69(60.5)$ & $138(57.3)$ & 0.339 & \\
Rural & $45(39.5)$ & $103(42.7)$ & & \\
\hline
\end{tabular}

Our results revealed attitudes that were associated with uptake of STI screening among AFSWs, risk of contracting STI ( $\left.\chi^{2}: 23.538, p=0.001\right)$; embarrassing to screen for STI $\left(\chi^{2}: 45.146, p=0.001\right)$; STI screening painful $\left(\chi^{2}: 57.019, p=0.001\right)$; Screening for STI makes one worry $\left(\chi^{2}: 16.584, p=0.001\right)$ and advising another AFSW to screen for STI $\left(\chi^{2}: 15.823, p=0.001\right)$, see Table 2. 
Table 2

Bivariate analysis of attitudes of AFSWs influencing uptake of STI screening in Mukono district

\begin{tabular}{|c|c|c|c|c|}
\hline Variable & $\begin{array}{l}\text { Uptake } \\
\text { (\%) }\end{array}$ & $\begin{array}{l}\text { No } \\
\text { uptake } \\
\text { (\%) }\end{array}$ & $\chi^{2}$ & $\begin{array}{l}\mathrm{P} \text { - } \\
\text { value }\end{array}$ \\
\hline \multicolumn{5}{|l|}{$\begin{array}{l}\text { Sexually transmitted infections is a public health } \\
\text { problem }\end{array}$} \\
\hline \multicolumn{5}{|l|}{$\begin{array}{l}\text { Yes } \\
\text { No } \\
\text { One thinks she is risk of contracting STI }\end{array}$} \\
\hline \multicolumn{5}{|l|}{$\begin{array}{l}\text { Yes } \\
\text { No } \\
\text { I don't know } \\
\text { Older FSWs are more likely to screen for STI }\end{array}$} \\
\hline $\begin{array}{l}\text { Yes } \\
\text { No } \\
\text { It is too embarrassing to screen for STI }\end{array}$ & $\begin{array}{l}67(58.8) \\
47(41.2)\end{array}$ & $\begin{array}{l}161(66.8) \\
80(33.2)\end{array}$ & 2.174 & 0.140 \\
\hline \multicolumn{5}{|l|}{ Yes } \\
\hline No & $\begin{array}{l}46(40.4) \\
68(59.6)\end{array}$ & $\begin{array}{l}185(76.8) \\
56(23.2)\end{array}$ & 45.146 & $0.001 *$ \\
\hline No & $\begin{array}{l}61(53.5) \\
53(46.5)\end{array}$ & $\begin{array}{l}215(89.2) \\
26(10.8)\end{array}$ & 57.019 & $0.001 *$ \\
\hline $\begin{array}{l}\text { No } \\
\text { Presence of male screeners in health facilities is a } \\
\text { reason for screening }\end{array}$ & $\begin{array}{l}93(81.6) \\
21(18.4)\end{array}$ & $\begin{array}{l}229(95.0) \\
12(5.0)\end{array}$ & 16.584 & $0.001 *$ \\
\hline \multicolumn{5}{|l|}{ Yes } \\
\hline The manner in which STI screening is performed & $54(47.8)$ & $131(54.6)$ & 1.423 & 0.233 \\
\hline Yes & $59(52.2)$ & $109(45.4)$ & & \\
\hline No & & & & \\
\hline
\end{tabular}




$\begin{array}{|lllll|}\text { Self-obtained sampling is more comfortable than } & & & & \\ \text { provider-obtained sampling } & 51(44.7) & 116(48.1) & 0.358 & 0.549 \\ \text { Yes } & 63(55.3) & 125(51.9) & & \\ \text { No } & & & & \\ \text { I don't know } & & & & \\ \text { Lack of information about STI screening procedure } & 84(73.7) & 196(81.3) & 3.096 & 0.213 \\ \text { Yes } & 12(10.5) & 15(6.2) & & \\ \text { No } & 18(15.8) & 30(12.4) & & \\ \text { Would advise another AFSW to go for STI screening } & & & & \\ \text { Yes } & & & & \\ \text { No } & & & & \\ \text { Cultural beliefs affect your uptake of STI screening } & 97(85.1) & 215(89.2) & 1.236 & 0.266 \\ \text { Yes } & 17(14.9) & 26(10.8) & & \\ \text { No } & & & & \\ \end{array}$

\section{Correlation is significant at, ${ }^{*} p<.05,{ }^{* *} p<.01,{ }^{* \star} p<.001 ; \chi^{2}-$ Chi-Square}

Among the health facility factors that the study assessed, our findings revealed that distance $\left(\chi^{2}: 10.335\right.$, $p=0.035)$; sensitization on STIs and their screening $\left(\chi^{2}: 15.307, p=0.001\right)$; Waiting time $\left(\chi^{2}: 9.731, p=\right.$ $0.021)$; presence of follow-up system $\left(\chi^{2}: 11.488, p=0.001\right)$; adolescent friendly clinic at your nearest health facility $\left(\chi^{2}: 12.985, p=0.001\right)$ and provision of STI screening services at nearest facility $\left(\chi^{2}\right.$ : $18.714, p=0.001)$ were significantly associated with uptake of STI screening among AFSWs as shown in Table 3. 
Table 3

Bivariate analysis of health facility factors influencing uptake of STI screening in Mukono district

\begin{tabular}{|c|c|c|c|c|}
\hline Variable & $\begin{array}{l}\text { Uptake } \\
\text { (\%) }\end{array}$ & $\begin{array}{l}\text { No uptake } \\
(\%)\end{array}$ & $\chi^{2}$ & $\begin{array}{l}\mathrm{p}- \\
\text { value }\end{array}$ \\
\hline \multicolumn{5}{|l|}{ Distance } \\
\hline$<1 \mathrm{~km}$ & 14(12.3) & $11(4.6)$ & 10.335 & $0.035^{*}$ \\
\hline $1 \mathrm{~km}$-2miles & $23(20.2)$ & $43(17.8)$ & & \\
\hline 2miles-5miles & $45(39.5)$ & $89(36.9)$ & & \\
\hline$>$ 5miles & 15(13.2) & $49(20.3)$ & & \\
\hline I do not know & 17(14.9) & $49(20.3)$ & & \\
\hline \multicolumn{5}{|l|}{$\begin{array}{l}\text { Sensitization on sexually transmitted infections and } \\
\text { their screening }\end{array}$} \\
\hline \multicolumn{5}{|l|}{ Yes } \\
\hline \multicolumn{5}{|l|}{$\begin{array}{l}\text { The lack of convenient clinic time is a barrier to } \\
\text { routine STI screening }\end{array}$} \\
\hline \multicolumn{5}{|l|}{ Yes } \\
\hline No & $67(58.8)$ & $131(54.4)$ & 0.612 & 0.434 \\
\hline Pay for sexually transmitted infection screening & $47(41.2)$ & $110(45.6)$ & & \\
\hline \multicolumn{5}{|l|}{ Yes } \\
\hline No & 18(15.9) & $51(21.4)$ & 1.467 & 0.226 \\
\hline Waiting time at health facility & $95(84.1)$ & 187(78.6) & & \\
\hline \multicolumn{5}{|l|}{$<30 \mathrm{~min}$} \\
\hline $30 \mathrm{~min}-1 \mathrm{hrs}$ & $11(9.6)$ & $16(6.6)$ & 9.731 & $0.021 *$ \\
\hline $1 \mathrm{hr}-2 \mathrm{hrs}$ & 21(18.4) & $40(16.6)$ & & \\
\hline$>2 \mathrm{hrs}$ & $45(39.5)$ & $66(27.4)$ & & \\
\hline $\begin{array}{l}\text { There a system in place at your nearest facility to } \\
\text { follow up clients }\end{array}$ & $37(32.5)$ & $119(49.4)$ & & \\
\hline \multicolumn{5}{|l|}{ Yes } \\
\hline \multicolumn{5}{|l|}{ No } \\
\hline $\begin{array}{l}\text { There an adolescent friendly clinic at your nearest } \\
\text { health facility }\end{array}$ & $46(40.4)$ & $143(59.6)$ & 11.400 & 0.001 \\
\hline Yes & & & & \\
\hline
\end{tabular}




\begin{tabular}{lllll|} 
No & & & & \\
Availability of screening service & $89(78.1)$ & $141(58.5)$ & 12.985 & $\mathbf{0 . 0 0 1 *}$ \\
Yes & $25(21.9)$ & $100(41.5)$ & & \\
No & & & & \\
I don't know & $110(96.5)$ & $222(92.1)$ & 3.943 & 0.139 \\
Nearest facility to where you live provides STI & $2(1.8)$ & $3(1.2)$ & & \\
screening & $2(1.8)$ & $16(6.6)$ & & \\
Yes & & & & \\
No & & & & \\
I don't know & $101(88.6)$ & $164(68.0)$ & 18.714 & $\mathbf{0 . 0 0 1 *}$ \\
Religious beliefs influence your uptake of STI & $6(5.3)$ & $19(7.9)$ & & \\
screening & $7(6.1)$ & $58(24.1)$ & & \\
Yes & & & & \\
No & & & & \\
& & & & \\
& $17(14.9)$ & $45(18.7)$ & 0.759 & 0.384 \\
& $97(85.1)$ & $196(81.3)$ & & \\
\end{tabular}

Our results indicate that AFSWs who reported STI screening wasn't embarrassing were more than 3 times likely to take-up STI screening than those who said uptake of STI screening was embarrassing $(P R=3.45$, $95 \% \mathrm{Cl}=1.96-6.09, \mathrm{P}=0.001)$. AFSWs who said STI screening wasn't painful were more than 5 times likely to take-up STI screening than those who said uptake of STI screening was painful (PR $=5.45$, $95 \% \mathrm{Cl}=2.78-10.66, \mathrm{P}=0.001)$. AFSWs who said screening for STI will not make one worry were almost 4 times likely to take-up STI screening than those who said screening for STI will make one worry (PR = $3.74,95 \% \mathrm{Cl}=1.37-10.17, \mathrm{P}=0.010)$. Those who said they can't advise another AFSW to take up STI screening were 0.2 times less likely to go for STI screening than those who said they can advise another AFSW (PR $=0.25,95 \% \mathrm{Cl}=0.09-0.70, \mathrm{P}=0.009)$. Those who said they don't have STI screening at the nearest facility to where they live were 0.2 times less likely to go for STI screening than those who said they have STI screening at the nearest facility to where they live $(P R=0.20,95 \% \mathrm{Cl}=0.07-0.54, P=0.002)$. Those who said they don't have an adolescent friendly clinic in the nearest facility were 2 times more likely to take up STI screening than those who said the adolescent clinic was available $(P R=2.42,95 \% \mathrm{Cl}$ $=1.22-4.82, P=0.012)$. Using the binary logistic regression analysis model with $L / R$ forward, the summary model generated $R^{2}=40.7 \%$. This means that the factors generated as influencing factors can only explain $40.7 \%$ of the observed situation, see Table 4 
Table 4

Multivariate analysis of factors associated with uptake of sexually transmitted infection screening

\begin{tabular}{|c|c|c|c|}
\hline Variable & $\begin{array}{l}\text { PR } \\
(95 \% \mathrm{Cl})\end{array}$ & $\begin{array}{l}\text { APR } \\
(95 \% \mathrm{Cl})\end{array}$ & $\begin{array}{c}\mathrm{p}- \\
\text { value }\end{array}$ \\
\hline \multicolumn{4}{|l|}{ It is too embarrassing to screen for STI } \\
\hline Yes & $0.21(0.31-0.33)$ & 1 & 0.001 \\
\hline No & 1 & \multirow{3}{*}{$\begin{array}{l}3.45 \\
(1.96- \\
6.09)\end{array}$} & \\
\hline STI screening is painful & & & \\
\hline Yes & $10.14(0.08-0.24)$ & & 0.001 \\
\hline No & 1 & 1 & \\
\hline \multicolumn{2}{|l|}{ Screening for STI will make one worry } & \multirow{3}{*}{$\begin{array}{l}5.45 \\
(2.78- \\
10.66)\end{array}$} & \\
\hline Yes & $0.23(0.11-0.49)$ & & 0.010 \\
\hline No & 1 & & \\
\hline \multicolumn{2}{|l|}{$\begin{array}{l}\text { Would advise another AFSW to go for STI } \\
\text { screening }\end{array}$} & \multicolumn{2}{|l|}{1} \\
\hline \multicolumn{2}{|l|}{ Yes } & \multirow{3}{*}{$\begin{array}{l}3.74 \\
(1.37- \\
10.17)\end{array}$} & \\
\hline No & $5 . / 1(2.21-14 . / 4)$ & & 0.009 \\
\hline \multicolumn{2}{|l|}{$\begin{array}{l}\text { Nearest facility to where you live provide STI } \\
\text { screening }\end{array}$} & & \\
\hline \multicolumn{2}{|l|}{ Yes } & \multicolumn{2}{|l|}{1} \\
\hline \multicolumn{2}{|l|}{ No } & \multirow{5}{*}{$\begin{array}{l}0.25 \\
(0.09- \\
0.70)\end{array}$} & \multirow{4}{*}{0.002} \\
\hline \multirow{2}{*}{$\begin{array}{l}\text { Availability of adolescent friendly clinic at } \\
\text { nearest health facility } \\
\end{array}$} & $5.10(2.24-11.62)$ & & \\
\hline & $12.53(1.51-4.21)$ & & \\
\hline res & 1 & & \\
\hline \multirow{4}{*}{ No } & & & \\
\hline & & 1 & 0.012 \\
\hline & & \multicolumn{2}{|l|}{$\begin{array}{l}0.20 \\
(0.07- \\
0.54)\end{array}$} \\
\hline & & 1 & \\
\hline
\end{tabular}




\section{Discussion}

\section{Uptake of STIs screening}

This study found that the uptake of STI screening rate was at $32.1 \%$. This is probably due to AFSWs attitudes including STI screening being embarrassing, painful, makes one worry and advising another AFSW to go for STI screening as well as health facility factors including provision of STI screening in the nearest health facility and availability of adolescent friendly clinic as these proved to be statistically significant variables which influenced uptake of sexually transmitted infection screening at different levels of analysis.

In a USA study among AFSWs, Roth et al. 2013 , found out that $90 \%$ of AFSWs had not screened for STIs yet $88 \%$ of other women reported willingness to screen only if they were allowed to collect their own sample. This is in agreement with the 2010 US Federal and prostitution law report on FSWs in which it was stated that the prevalence of STIs was higher among FSWs than other women such as migrants, adding that it was due to neglect of screening uptake amidst high risk sexual behavior that results in worse sexual health outcomes.

\section{Socio-demographic Factors And Uptake Of Sti Screening}

Our study findings show that $241(67.9 \%)$ of the respondents were in the age group of in 15-19years, older than other respondents in the age group of 10-14 years 114 (32.1\%), possibly because currently AFSW 15-19 years are more exposed to independent life without any parenteral or guardian restrictions to movement, social networking and peer influence.

Majority of those who had screened were in the age group of 15-19 years, an indicator that older AFSWs were more likely to takeup STI screening than their counterparts in the age group of 10-14 years, and this may be possibly due to the fact thet they can easily access information that enables them undestand, that they are at risk of acquiring STIs by nature of their job than those aged 10-14 years. Our study also revealed that an AFSWs age $\left(\chi^{2}: 1.864, P=0.172\right)$ was not found to influence STI screening uptake. This is supported by a Nigerian study carried out by Erin et al., (2013), in which female adolescents in transactional sex reported that they wanted to get information from parents and providers about STIS and its screening but parents did not provide it adding that given their discreet sexual behavior, frequent asking of their parents on this topic would lead to unexpected eventualities including dismissal from home. Contrary to this, Chakuvinga et al., (2017) found out that the AFSWs perceived themselves as young, not susceptible and therefore, not bothered about STI screening issues and the older sex workers 
found it difficult to discuss this with the young ones for them to clearly understand and change their perception hence this poor relationship affected STI screening uptake.

In this study, none of the socio-demographic factors had a significant relationship with the uptake of STI screening among AFSWs unlike in another Ugandan study carried out by Mbonye et al., 2013, whichrevealed that some socio-demographic factors including the age group, years of sex work practice and residence of an AFSW influenced their uptake of STI screening.

\section{Attitudes Towards Sti Screening}

In our study, majority $59.6 \%$ of the respondents reported that it was not too embarrassing to screen for sexually transmitted infections. This can be attributed to their past experience with uptake of STI screening. AFSWs who said STI screening wasn't embarrassing were 3 times more likely to take-up STI screening than those who said uptake of STI screening was embarrassing. This is contrary with a USA study among AFSWs, in which Malla and Goyal, (2012) reported that participants (87\%) indicated willingness to recommend self-sampling to a friend because they felt having a clinician collect a sample was awkward and embarrassing.

From this study findings, $81.6 \%$ of the respondents said screening for STIs will make one worry. This is true because of the uncertainty of the test result amidst the already known high risk job circumstances and exposure of these AFSWs. There was a significant relationship between being worried and uptake of STIs screening $\left(\chi^{2}: 16.584, p=<0.001\right)$ at 0.05 level of significance. AFSWs who said screening for STI will not make one worry were 4times more likely to take-up STI screening than those who said screening for STI will make one worry. This could be because they knew they were at risk of acquiring STI and were highly suspecting to have an STI, they were possibly therefore willing to take up STI screening for early diagnosis to be started on treatment just in case they had positive test result or to be advised on how to prevent themselves from acquiring STIs if given a negative test result.

\section{Health Facility Factors And Uptake Of Sti Screening}

In this study, $96.5 \%$ said STI screening services were available in Mukono district and majority $78.1 \%$ said that they had an adolescent friendly clinic at the nearest facility to where they lived. However, in this study, findings are that those who said they don't have an adolescent friendly clinic in the nearest facility were 2 times more likely to take up STI screening than those who said the adolescent clinic was available. This is possibly due to the fact that the services are widely provided by the $\mathrm{MOH}$ through health facilities in outreaches or camps which are not consistently organized at specific facilities/adolescent friendly clinics near to where they live. In another high-prevalence cohort in India, Das, et al. (2011) reported that participants indicated that being screened for STIs outside of a clinic setting would provide a more feasible option for taking up STI screening. Similar to this was in Ethiopia, Adisababa where Cherie and Berhane (2012) reported that clinic systems were not usually oriented to providing youth with 
reproductive health screening especially for STIs. This frequently led to the perception that SRH services and the systems themselves were 'not for youths' which overlapped with barriers related to acceptability of services

In Uganda, non-government organizations have single handedly or have partnered with $\mathrm{MOH}$ to stage organized screening outreaches and camps not necessarily at health facilities that have targeted high risk groups. This is supported by this study findings in which most $55.2 \%$ of those that screened accessed screening services at non- clinical sites such as outreaches than at health facilities. In this current study, there was an association between availability of adolescent friendly clinic in the nearest health facility and uptake of STI screening $\left(\chi^{2}: 12.985, p=<0.001\right)$

Failure to screen at adolescent clinic can also be attributed to the long distance that had to be travelled to reach the nearest health facilities with an adolescent clinic in relation to the providers who bring screening services nearer to targeted users.

The study revealed that $88.6 \%$ of the respondents said STI screening was provided at the nearest facility to where they lived. This can be true because the government of Uganda through the $\mathrm{MOH}$ has established and integrated reproductive health services including screening within existing health facilities to ease access and facilitate acceptability among even high risk and vulnerable groups such as AFSWs. In this current study, there was a significant relationship between provision of STI screening in the health facilities and uptake for STI screening $\left(\chi^{2}: 18.714, p=<0.001\right)$ at 0.05 level of significance at bivariate level as evidenced by a $p$ value less than 0.05 . On further analysis at multivariate level, those who said they don't have STI screening at the nearest facility to where they live were 0.2 times less likely to go for STI screening than those who said they have STI screening at the nearest facility to where they live. This corresponds with findings in Uganda where STI screening services are widely available even in some resource-limited settings, but not enough. Rapid diagnostic tests for STIs other than syphilis are not currently available and due to lack of a reliable source of funding for procurement. In addition, some of the screeners have inadequate training to provide screening services. This highly affects the health seeking behavior of high-risk populations turning up for screening ( $\mathrm{MOH} 2018)$

\section{Conclusions}

In this study where sexually transmitted infection screening rates among AFSWs in Mukono district was still low at $32.1 \%$ which is still far below the national average of $80 \%$ for eligible women, individual factors (attitude) and health facility factors were found to be the real influencers of uptake of STI screening among AFSWs in Mukono district. It's important for government to scale-up/intensify provision of information related to STIs and its screening at clinical and non-clinical sites such as the possibility of STI community-based self-sampling among adolescents to increase awareness and improve accessibility to STI screening experience among high risk vulnerable groups in Mukono district so as to reduce the prevalence among AFSWs. 


\section{List Of Abbreviations}

\begin{tabular}{ll} 
AFSWs & Adolescent Female Sex Workers \\
CDC & Centre for Disease Control \\
CI & Confidence Interval \\
DHO & District Health Officer \\
\hline FCSWs & Female Commercial Sex Workers \\
\hline FSWs & Female Sex Workers \\
\hline HIV & Human Immune Virus \\
\hline MOH & Ministry Of Health \\
\hline NGOs & Non-Government Organization \\
PR & Prevalence Ratio \\
APR & Adjusted Prevalence Ratio \\
\hline RH & Reproductive Health \\
\hline STDs & Sexually Transmitted Diseases \\
\hline STIs & Sexually Transmitted Infections \\
\hline SRHR & Sexual and Reproductive Health and Rights \\
\hline UBOS & Uganda Bureau Of Statistics \\
\hline UMU & Uganda Martyrs University \\
\hline UNAIDS & Joint United Nations Programme on HIV/AIDS \\
\hline WHO & World Health Organization \\
\hline
\end{tabular}

\section{Declarations}

\section{Ethics approval and consent to participate}

Ethical approval was sought from Uganda Martyrs University ethics and research committee and permission to carry out the study was sought from Mukono District Health Officer (DHO) and local council authorities as required by the regulation. Study respondents were informed and given clear explanation of the study purposes, objectives and assurance of voluntary basis for study participation with no reward or penalty for participation or decline to participate in the study.

\section{Consent for publication}




\section{Availability of data and materials}

Available from the corresponding author on reasonable request.

\section{Competing interests}

No competing interests available

\section{Funding:}

$\mathrm{N} / \mathrm{A}$

\section{Authors' contributions}

NJ participated in study conception and design; collected data, performed analyses and interpreted it; and drafted the manuscript. MN participated in study conception and design; supervised data collection; helped in data analyses and revision of the manuscript. All authors read and approved the final manuscript.

\section{Acknowledgements}

Akugizibwe Pardon (AP) in the Department of Health Policy, planning and Management at Clarke International University participated in study conception and revision of the manuscript.

\section{Authors' information (optional):}

N/A

\section{References}

1. Chakuvinga P, Scorgie F, Nakato D, Akoth DO, Netshivhambe M, Nkomo P, et al. 2017. "I expect to be abused and I have fear": sex workers' experiences of human rights violations and barriers to accessing healthcare in four African countries. Final report. African Sex Workers Alliance, 2011 (online) Available at: <https://www.ncbi.nlm.nih.gov/pmc/articles/PMC5515058/>(Accessed 20 December 2018) 
2. Cherie A, Berhane Y., 2012. Knowledge of Sexually Transmitted Infections and Barriers to Seeking Health Services among High School Adolescents in Addis Ababa, Ethiopia, Journal of AIDS \& Clinical Research (online) Available at: < https://www.omicsonline.org/knowledge-of-sexually-transmittedinfections-and-barriers-to-seeking-health-services-among-high-school-adolescents-in-addis-ababaethiopia-2155-6113.1000153.php?aid=6646>(Accessed28 December 2018)

3. Das A, Prabhakar P, Narayanan P, Neilsen G, Kumta T. Wi, S., G. Rao, Gangakhedkar R, and Risbud .A., Jyoti 2011. Prevalence and Assessment of Clinical Management of Sexually Transmitted Infections among Female Sex Workers in Two Cities of India, Journal of Infectious Diseases of Obstetrics and Gynaecology, (online) Available at: < https://www.ncbi.nlm.nih.gov/pmc/articles/PMC3124070/> (Accessed 16 December 2018)

4. Erin P, Nuha C, Louis A, Marguerite TN, Odette KZ, Claire H, Fatou MD, Ashley G, Daouda D, and Stefan DB., 2013. Epidemiology of HIV among female sex workers, their clients, men who have sex with men and people who inject drugs in West and Central Africa, Journal of the International AIDS Society,(online) Available at: <https://www.ncbi.nlm.nih.gov/pmc/articles/PMC3852130/> (Accessed 21 February 2019)

5. Malla, N. and Goyal, K. 2012. Sexually Transmitted Infections: An Overview. In: Malla, N., Ed., Sexually Transmitted Infections, Chap. 1, (online) Available at:< https://pdfs.semanticscholar.org/ea2f/91d6ec42a83058de524828cc1c450d416eec.pdf> (Accessed 16 January 2019)

6. Mbonye M, Nakamanya S, Nalukenge W, King R, Vandepitte J, Seeley J, 2013. Structure and practices of female sex work in Kampala, Uganda. BMC Public Health Article, (Online) Available at: <https://www.ncbi.nlm.nih.gov/pubmed/23938037> (Accessed 01 March 2019)

7. MOH. Annual Health Sector Performance Report. Kampala: Ministry of Health; 2018.

8. Roth $A M^{1}$, Rosenberger JG, Reece M, Van Der Pol B, 2013. Expanding sexually transmitted infection screening among women and men engaging in transactional sex: the feasibility of field-based selfcollection, International Journal of STD and AIDS, (online) Available at: <https://www.ncbi.nlm.nih.gov/pubmed/23970665> (Accessed 20 February 2019)

9. The Joint United Nations Programme on HIV and AIDS, 2014. The Gap Report (pdf) Sub-Saharan Africa: unaids. Available at:< www.unaids.org/sites/default/files/media_asset/UNAIDS_Gap_report_en.pdf.> (Accessed December 15, 2017).

10. Urasa,M., \& Darj,E. 2011. Knowledge of screening practices of nurses at a Regional Hospital in Tanzania.african Health Science (Online) Available at < https://www.ncbi.nlm.nih.gov/pmc/articles/PMC3311084/> (Accessed 12 January 2019)

11. UNFPA, United Nations Population Fund. 1994. International Conference on Population and Development Report, Cairo, 5-13 September 1994, Egypt: United Nations.

12. World Health Organization. 2019. Sexually Transmitted Infection Key facts sheet WHO. Available at < https://www.who.int/news-room/fact-sheets/detail/sexually-transmitted-infections-(stis) (Accesses 
April 2019).

13. World Health Organization, 2016. Global health sector strategy on Sexually Transmitted Infections, 2016-2021..Geneva. World Health Assembly: Available at: < https://www.who.int/reproductivehealth/publications/rtis/ghss-stis/en/>(Accessed on 18 January 2019)

\section{Figures}

\section{$67.90 \%$}

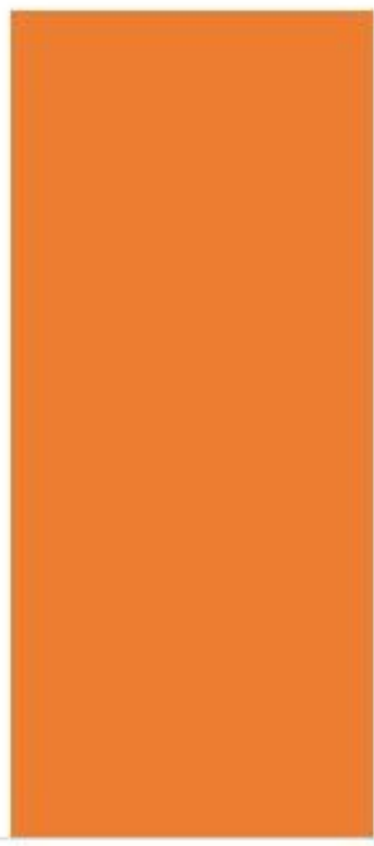

Screened

Never screened

\section{Figure 1}

Level of uptake of STI screening among adolescent sex workers in Mukono district 